\title{
Agents skills and their roles in mobile computing and personal communications
}

\author{
M. Mendes ${ }^{*}$, W. Loyolla ${ }^{*}$, T. Magedanz ${ }^{+}$, F. M. Assis Silva ${ }^{+1}$, S. Krause ${ }^{+}$ \\ ${ }^{*}$ Pontifícia Universidade Católica de Campinas (PUCCAMP) \\ Campinas, S.P. Brazil, Email: mendes@dca.fee.unicamp.br \\ ${ }^{+}$Research Institute for Open Communication Systems (GMD FOKUS) \\ Berlin, Germany,Email: [magedanzlkrauselflavio]@fokus.gmd.de
}

\begin{abstract}
In the context of the emergence of a global service market enabling the ubiquitous access to information and communication services, the new paradigm of mobile intelligent agents is attracting strong interest throughout the research community, as well as the information and telecommunication industries. After giving a brief account of the development of the agent paradigm and the basic terminology, this paper analyzes different application fields of this highly promising technology. Among the reviewed application areas are electronic markets, virtual enterprises, flexible information systems, and the domain of mobile and personal communications. The analysis leads to the identification of a number of roles agents may take on. The capabilities that an agent exhibits in the course of performing its role can be expressed as levels of agent intelligence, mobility, communicability, autonomy and cooperation ability, i.e. the agents skills.
\end{abstract}

\section{Keywords}

Agents, agent roles, agent skills, electronic markets, flexible information systems, mobile computing, personal communications, virtual enterprises

\section{INTRODUCTION}

The vision for future telecommunications and information networking environments is often described as "information at any time, at any place, in any form". The envisioned ubiquitous information access will result in an open "electronic" service market, where an unlimited spectrum of communication and information services will be offered to the customers, ranging from simple communication services to complex distributed applications. This vision is based on both, the society's increasing demand for "universal connectivity" and on the technological progress in the emerging areas of mobile computing and mobile/personal telecommunications. The ultimate target is to support customer-controlled wired and wireless global access to information and telecommunication services, regardless of the customer's current

${ }^{1}$ The work of this author is partially supported by Conselho Nacional de Desenvolvimento Científico e Tecnológico (CNPq), Brazil 
location, or terminal and network capabilities. The realization of this target depends on the provision of an intelligent platform/environment, which is capable of adapting available information and telecommunication services, and the underlying systems and network resources according to the customers demands.

In this context the notion of Agents has evolved over the last years, as a new problemsolving paradigm, suited to a wide range of problem domains. The number of products, projects, and new applications using this paradigm is constantly growing, calling attention of the research community to study it and to propose solutions for several of the already detected problems.

The term agent is original of the Artificial Intelligence (AI) community, and its notion is central to the definition of $\mathrm{AI}$ itself. A common definition for $\mathrm{AI}$ is 'the sub-field of computer science that aims the construction of agents that exhibit aspects of intelligent behavior' (Wooldridge, 1994a).

Since the early 1970 s, the AI planning community has been closely concerned with the design of artificial agents. Nevertheless, until the middle of the 1980 s, researchers from mainstream AI had given relatively little consideration to the issues surrounding agent synthesis. However, from this time there has been an intense growing of interest in the subject \{Wooldridge, 1994a\}.

Nowadays several research projects and developing efforts concerning agent technology are on-going and cover a multitude of other areas, other than AI, but there is an agreement in almost all of them about the nature of the environment where agents exist, and this comprehends the massively distributed system.

Generally, an agent can be any entity (physical or logical) that is responsible for the execution of a set of tasks, delegated to it, directly or by means of other entities, by a user humanbeing. The agent represents the user while performing its cores, acting on the user's behalf.

Analyzing the R\&D projects, most of them developed by the AI community, it is possible to perceive that there are currently at least five major research sub-fields:

- Physical agents (robots), employing AI techniques to conceive them with human behavior. Most of the surveyed projects lie in this context. The emphasis in this sub-field is in the intelligent agent architecture, so these projects are closer related to IA. Although the architectures proposed are to robots, it seems that they can be modified to be employed in software agents, as was done in the Sumpy project \{Franklin, 1996\}

- Multi-agent systems, made up of multiple heterogeneous intelligent agents, where competition or cooperation is possible between them. There is no common application domain or global goal to be achieved. Projects in this second group cover the development of agents written by different people, in different languages, at different times for different purposes \{Dalmonte, 1995\}. This sub-field is directly concerned with the area of DAI (Distributed Artificial Intelligence);

- Task-specific agents, with the use of AI techniques to create software that performs information filtering and other autonomous tasks for users. "Intelligent" agents of this sort have been developed at Xerox PARC, at MIT's Media Lab, and by researchers at others companies and universities. These agents may or may not display any explicit anthropomorphic features;

- Interface Agents, as an interface metaphor that aids the user. These agents may or may not incorporate new AI techniques; their essential function is to act as effective bridges between a person's goals and expectations and the computer's capabilities. The agent metaphor is used to make the interface more intuitive and to encourage types of interactions that might be difficult to evoke with a GUI. Agents of this sort need not to be explicitly anthro- 
pomorphic, although this is the arena where the expressive qualities of 'character' are being explored;

- Mobile agents: It seems that these projects do not intent to use high levels of intelligence skill. (Tele)Communication industries are the main interested in this research field. In this context agents will be used for customization of existing services and configuration of new services \{Magedanz, 1996c \}.

In accordance to the environment where the agent inhabits, there can be physical agents, such as robots, or software agents, such as programs running on a computer. The scope of the present survey and resulting analysis is to use the term agent technology concerning to software agents. In Section 2 of the paper some agent applications are reviewed in order to better characterize the numerous roles that agents may play. Issues related to multi-agent systems, intelligent agents, interface-agents, and mobility should not be treated as separate aspects, but yet as complementary aspects that, if combined, can result in very powerful software agents for the support of an unlimited set of tasks. Thus those issues are conceptualized and worked on in Section 3, in order to allow a broader and more generic definition of what an agent is. In Section 4 some conclusions are drawn.

\section{AGENT APPLICATIONS}

In the following analysis applications are briefly described in order to better understand the extent of agents potential use. To this end we outline some agent applications in Virtual Environments, with emphasis in two high level application areas, and three supporting areas. The two high level applications areas are Electronic Commerce, and Virtual Enterprises, and the supporting areas Flexible Information Systems, Mobile Computing and Mobile Communication.

Electronic Market was chosen since it is an area of current explosive growing interest, not just to the commercial community but also to the academic community. Virtual Enterprise is a current and important research and standardization area which offers multiple opportunities to the use of agents.

Flexible Information Systems, which are the basis of all information manipulation, and Mobile Computing and Communication, by their very nature, are basic support facilities not just to the analyzed high level application areas but also to almost anyone collaborative application in the near future.

Mobile Communication and Mobile Computing are considered, since these are the key aspects of an emerging ubiquitous computing environment, where universal access to information, communication and services is provided.

\subsection{Electronic Market}

The term "electronic market" has been used in various ways, frequently referring just to few parts of commercial transactions. Electronic markets may be considered as hybrid systems, in which people and computers are working together in order to reach certain commercial results. In order to represent a real market in an electronic form, the "electronic market system" has to offer support to all possible transactions in a marketing process.

A generic market transaction is \{Klein, 1994\} "a finite sum of interaction processes between members of different roles". The participants try in a certain period of time to settle their interests and expectations amongst themselves. The aim of a market transaction is a trading agreement between the actors, supplier and customer, and the following settlement of 
goods and/or services. In some markets, their may exist intermediaries like dealers, brokers or market makers who perform some supporting functions in order to improve the efficiency of the transaction process.

Interaction processes in a market transaction can be combined in three phases: Information phase, Trading/matching phase and the Settlement phase. Supporting these phases requires an Electronic Market Information System who may be defined \{Klein, 1994\} as "an information system, embedded in the context of an electronic market, in order to automate or to support electronically the interaction processes between the actors in a market".

The use of agents in the realm of electronic commerce may have a explosive growth in the next few years. Currently, some emblematic experiences have been already done by offering the work of some agents in the WWW. These experiences cover aspects as finding people who have their own tastes (Agents Incorporation's Firefly) \{Agent Incorporation, 1995\}; filtering news information to receive a personalized newspaper (IBM's Infosage) $\{$ IBM, 1995\}, or even searching for the cheaper site where to buy an CD.

Agents may be used in all phases of a market transaction as:

- Information - the main purpose is to search for, find, filter and present information required both by potential customers and potential suppliers. These tasks may be performed with different aspects as:

- directly searching in the net for potential suppliers on behalf of a buyer, accordingly to some personal rules or conditions. Agents could visit firm's virtual presence sites, searching for offerings or for desired goods and services;

- searching potential buyers (marketing research) in the net by placing agents in the sites where advertisements are presented or by asking people (or another agents) about their preferences. In this way, agents could acquire not just the buyers' preferences profile from keeping track their advertisement site navigation but also their addresses.

- indirectly searching for potential suppliers or buyers by contacting information traders or by purchasing information from special commercial sites who maintain commercial information.

- Trading/matching - the main purpose is to support the tasks involving negotiations. Agents, on behalf of the buyer, could negotiate with suppliers the terms and conditions of delivery and payment, warranties, and the execution or offering of additional services. In this case, agents could act at least in the following ways:

- traveling through the selected suppliers sites and asking them for a set of marketing conditions which could be sent to the buyer. In this case, the agent could:

- just pick the required information up and send it to the buyer;

- pick the required information up and provide some kind of information filtering, accordingly to some pre-defined rules established by the agent's owner. After that, the prepared information could be sent to the buyer.

- locally receiving invoices from selected suppliers, and, accordingly to pre-defined rules, to analyze them and to suggest a preferential supplier.

- performing some part of the negotiation. The results of preliminary negotiation would be submitted to both supplier and buyer for posterior formal approval.

- performing the whole negotiation. Both buyer and supplier are notified about final negotiation set.

- Settlement - agents could act both by:

- providing electronic payment; 
- following the occurrence of derived transaction processes related to the deal as packaging, storage, shipping, insurance, customs clearance, etc.

Despite not fulfilling the above electronic market system definition, the Internet and particularly the World Wide Web have been used as a commercial medium where firms are learning new ways of marketing to consumers in computer-mediated environments \{Hauser, 1995\}. In the next future it is expected that these experiences drive the evolution of complete Open Electronic Market Systems where almost all phases of market transactions can be electronically supported, probably running upon the Internet or new communication environments. Currently, many categories of commercial sites have been already defined and implemented in the Web \{Hoffman, 1996\}.

\subsection{Virtual Enterprises}

Virtual Enterprises correspond to a temporary alliance of companies formed to share costs and skills in order to address fast-changing commercial/industrial opportunities by providing competitive products, services and solutions cost-effectively and in a timely manner, regardless of size, organization, geographic or technical boundaries. Its members carry out their tasks as if they all belong to the same organization, under one roof, using a very powerful computing system to access and manage all information needed to support the product or service life-cycle. Yet, in reality they are employees of different companies, located abroad in the world, using a variety of computing systems and applications \{NIIIP, 1996b\}. The powerful computing system which offers support for this cooperation is called a Virtual Computing Environment.

Agents may be useful in all existence phases of a Virtual Enterprises as:

- Formation of a Virtual Enterprise - an agent owned by a virtual enterprise initiator could

- search for potential virtual enterprise partners by traversing the net and asking (directly or consulting some kind of yellow pages) for companies who may fulfill some desired production requirements or perform some required services;

- negotiate partners admittance after analyzing technical or commercial responses to participation requests accordingly to initiator limits and rules;

- negotiate workflow templates to be executed during the virtual enterprise existence,

- search and install appropriate software supporting the needed protocols to facilitate the operation of the virtual enterprise (workflow execution);

- scheduling and completing projects - agents could be used to monitor remote status of resources and services execution in order to reschedule local or global workflows;

- sharing information - remote placed agents could receive requests for product or service information and perform

- security verification for accessing information, so saving the transmission of unauthorized requests,

- data request format conversion in order to translate data requests to an understandable format for data repositories.

- data format translation in order to provide data understandable to requester.

- Collaborating on solving problems - agents could

- offer support on enabling groupwork such as controlling the use of groupware tools as whiteboards, shared sessions, and meeting schedulers, 
- offer support on controlling particular responsibilities due to virtual enterprise participant in a specific workflow,

- offer support on controlling the enactment of particular workflows;

- Communicating with organizations outside the VE - agents could be useful in:

- filtering incoming communications and routing them to the right partners' sites,

- offering information translation (mediation) between different application's information format;

- Negotiating, mediating and resolving disputes - agents could perform activities as

- searching information or services related to a specific matter of discussion,

- offering the owner's position related to a specific matter of discussion,

- summarizing voting related to a specific matter of discussion;

- Dissolving a $V E$ - agents owned by each virtual enterprise participant could act:

- searching for unfinished tasks related to the participation in a virtual enterprise,

- negotiating with other agents the responsibilities due by the participant after the dissolution of the virtual enterprise.

\subsection{Flexible Information systems}

The demand for tools to manage the vast amount of information has come with the explosive growth of network information systems, such as the one that can be found in the World Wide Web (WWW). The provision of information is a key prerequisite for a successful distributed information system. There is the need to concentrate on what can be done to supply the user with the required information, so that communications problems, location of the data, the amount of data to be manipulated, among other issues do not interfere with an adequate provision. Agent technology could play a major role in this context allowing the construction of Flexible Information Systems that can operate autonomously or in cooperation with other systems in order to satisfy the specific goals of users and applications supporting distributed information services over an heterogeneous distributed processing environment.

Information agents could act as intelligent and active front-ends, in the sense of being based on user preferences or patterns and on environmental conditions. Information agents could be created and launched by the user's computational environment in order to travel through the information network and bring information, or they could be created by an information server and launched to the user computational environment in order to bring information, after a process of offer and negotiation.

An information agent is an agent that, by itself or asking for cooperation, has access through network services to at least one, and potentially many information sources, and is able to collate and manipulate information obtained from these sources in order to answer queries posed by users and other agents. It can be added to this definition the ability of an information agent to sell and deliver information that was not initially of interest to the user.

Basically an information agent could be seen as an information trader, forager, cataloger, presenter, or combination of them with some degree of intelligence and mobility, and that is part of a cooperative information system.

Agent skills can produce very flexible cooperative information systems allowing that, for example:

- agents with knowledge - Foraging is one of the central issues in agent programming \{Harrison, 1994\} and the ideal system posses knowledge specific to the domain in which it 
operates and specific to the user's interests, as well as the ability to filter data based on this knowledge. This knowledge is also obtained through the exposure to a lot of current data related in the proper area of expertise. The difference between real semantic foraging and simple keyword searches is the amount of information that can be passed through the system to allow to it become a real expert in its field and to have high quality, current information at its disposal.

- mobile agents -To the extend that mobility allows the agents to get closer to the actual data source, mobility becomes a real advantage. It is far more efficient for a program extracting knowledge to go to the source of the data instead of sending the data to the user, especially since the program can primarily filter and summarize the data.

- dependency - Distributed intelligent agents, which are resident at the same local as the data sources and persist there of their own accord have a real advantage in this respect over centralized, more static systems. Thus an agent can do automatic indexing of documents, which will include identifying a small number of interesting documents from among a large number of uninteresting ones. It might also identify documents potentially interesting to other agents and inform them of this fact. Distributed indexes could be built up hierarchically, geographically, and by subject.

\subsection{Mobile/Personal Telecommunications}

In the light of an increasing number of wired and wireless communication services available for accessing and exchanging information, the vision for future communications, i.e. "information anytime, any place in any form", is becoming reality in the near future. However, besides the traditional aspect of information transport, the fundamental issue for new telecommunication services is information processing, i.e. the filtering, transformation and presentation of multimedia information in accord to customer needs, available communication networks and end systems currently used by the customer.

In addition to user and terminal mobility support, it will be the aspects of service customization and service interworking that are of fundamental importance for future telecommunications, enabling customers to define when, where, for whom and in what form they will be reachable or not. Consequently, adequate means are required to support end users in configuring their communications environment in accord to individual preferences.

Looking at today's mobile/personal communications systems, one will identify the Intelligent Network (IN) and the Telecommunications Management Network (TMN) standards as the basis for controlling and managing the user/terminal locations, user preferences and network resources. Current IN and TMN architectures are based on highly centralized approaches for the location of service control and network (and service) management "intelligence", where the related protocols rely on the traditional client/server paradigm. This means that centralized nodes, known as IN Service Control Points (SCPs) and TMN Operations Systems (OSs) are used for hosting service and management programs, respectively.

However, agent technology is considered as an emerging technology in this domain. The driving force for this view is the assumption that agents will provide better support for distribution of control and management in telecommunication systems in general \{Magedanz, 1995a, Magedanz 1996b, Magedanz, 1996c $\}$. This is due to the fact that the agent concept can be seen as an evolution step beyond the object-oriented paradigm, since agents enhance objects by distributing control and goals to them. This means that agents, i.e. their identified skills, such as intelligence, cooperation, asynchronous operation and agent mobility, allow to perform control and management tasks at the most appropriate locations within the telecommunications environment in contrast to existing architectures. This may have significant im- 
pacts on the architecture and the related (signaling) protocols of existing (mobile) telecommunication systems.

In principle, the following chances of emerging agent technology can be identified in the context of mobile communications \{Magedanz, 1996a\}:

- Customization and configuration of services: In the light of an electronic market place, agent technology allows to instantly provide new services either by customization or (re)configuration of existing services. In this case agents act as "service adaptors" and could be easily installed.

- Instant service usage and active trading: Mobile agents realizing service clients travel to potential customers providing spontaneous access to new services. This feature enabling easy distribution of service clients can be exploited to perform active trading.

- Decentralization of management: Mobile agents allow to decrease pressure on centralized network management systems and network bandwidth by delegating specific management tasks from central operations system to dispersed management agents. Mobile agents representing management scripts enable both temporal distribution (i.e. distribution over time) and spatial distribution (i.e. distribution over different network nodes) of management activities \{Magedanz, 1996a\}.

- Intelligent communications: Agents provide the basis for advanced communications. They support the configuration of a user's communications environment, where they perform control of incoming and outgoing communications on behalf of the end user. This includes communications screening, intelligent adaptation of services (i.e. conversion of information formats) to network access arrangements and end user devices, as well as advanced service interworking and integration \{Magedanz, 1996b).

- Information retrieval and support of dynamic information types: Mobile agents provide an effective means for retrieving information and services within a distributed environment and support for dynamic information types within electronic mail and advanced networked information systems.

In accord to the above given list two basic approaches of agent-based mobile/personal telecommunications can be identified:

- "Smart network" approach:

Agents are stationary entities in the network, providing the necessary intelligence, and are able to perform specific predefined tasks autonomously (on behalf of a user or an application). The basic attributes of this type of agent are their ability to act asynchronously, to communicate, to cooperate with other agents, and to be dynamically configurable. In order to enable this dynamic reconfiguration of the agent, the dynamic downloading and/or exchange of corresponding control scripts represents a fundamental issue. This means that this kind of static agent, such as user agents or management agents, could be considered more likely as a specialized agent execution environment, which executes scripts (i.e. remote execution type agents). Examples for such fixed agents are given in \{Eckardt, 1996\}, \{Ida, 1995\}, \{Mohan, 1995\}, \{Lauer, 1995\}, and \{Rizzo, 1995\}.

- "Smart message" approach:

Agents are mobile entities, which travel between different computers/systems and perform specific tasks at remote locations. In respect to the task to be performed either remote execution agents or migration agents may be deployed. Consequently, a mobile 
agent contains all necessary control information (i.e. the service logic of a particular telecommunications or management service), instead of the corresponding end systems and /or nodes within the network. This means that corresponding agent execution environments have to be provided by the potential end user systems and within the network, in order to perform the execution of agents and thus the realization of the intended services. Architectures promoting mobile agent-based services are AT\&T's PersonaLink and IBM's Intelligent Communications \{Reinhardt, 1994\}.

\subsection{Mobile computing}

The evolution of computing and telecommunications are bringing new ways of their use. The main shift is in the direction of nomadic computing and communications. The "nomadic" property refers to the system support needed to provide services to the nomad as he/she moves from place to place. This new paradigm is already manifesting itself as users travel to many different locations with laptops, PDAs , cellular telephones, and so on.

Mobile Computing Systems are a combination of the following three elements (Mazer, 1995\}:

- Stationary computer and network devices, which we will call the "infrastructure";

- Mobile computers, of varying physical properties ( such weight, size, and power) and computational capabilities, which will likely be "resource-poor" relative to the infrastructure;

- Wireline and wireless communications channels of varying bandwidth, cost, reliability, and service properties.

There are many motivations for using mobile agents in this mobile environment \{Chess, $1995\}$

- Support to lightweight devices;

- necessity of asynchronous methods of searching for information or transaction services;

- the reduction of overall communication traffic over the diverse communication channels that a mobile device may encounter;

- the ability of the agent to engage in a efficient communication with remote servers;

- the ability of the simple mobile computer to interact with complex applications, without necessarily knowing the remote server capabilities;

- the ability to create "personalized services" for the user, by tailoring the agents that move to the server and respond to the user's requests.

Two examples are now considered, one of an intelligent nomadic Information Systems \{Bgrodia, 1995\}, and the other from ubiquitous computing [Want, 1995\}.

The vast number of clients and servers interconnecting in a nomadic information system cause new problems in respect to the diversity of data formats, data consistency requirements, data schema and bandwidth limitations. Data servers need to have improved resource discovery facilities with a set of intelligent agents to provide searching and adaptive matching of resources. Based on context, user profile and current operating environment the CoBase Project $\{\mathrm{Chu}, 1996\}$ introduces adaptive agents. Agents in this complex situation must present several abilities:

- Different agents interact to achieve a common task and may use the output of other agents as input;

- they communicate with each other through some Agent Communication; 
- new concepts and algorithms need to be developed for performing negotiations, recovery, commitments;

- agents may be replicated and reused, thus needing a scaleable infrastructure.

The philosophy of Ubiquitous Computing aims to enrich processing by embedding into the environment many computing devices of different types, both personal and anonymous, fixed and mobile, large and small, and by using the virtual and physical context to provide more flexible personal access to information.ParcTab \{Want, 1995\} describes a representative project under development at the CSL from XEROX PARC. TAB is shorthand for "Small Tablet Computer" . A multilayer system architecture integrates the ParcTab devices into the PARC Office Network so that network applications can easily control and respond to the mobile devices. The TABs act primarily as input/output devices that rely on workstation-based applications for most computation. For each ParcTab there is exactly one agent which acts like a switchboard to connect applications. The agent performs four functions:

- it receives requests from applications to deliver packets to the mobile ParcTab that it serves;

- In the reverse direction, it forwards messages from its tab to the applications;

- it provides the source of Tab location information;

- It manages application communication channels.

\subsection{An Agent Role Classification}

Software agents may be further subdivided in the following classes:

- Group enabling agents: these agents support short-lived or long-lived collaborations. Several examples may be considered as:

- meeting schedulers;

- conferencing tools administrators;

- notificators;

- task activators;

- mediators;

- negotiators;

- facilitators: enable the joining of agents in cooperating groups of agents and provide the sharing of operations among them;

- User Agents: they represent and act on behalf of the users and operators (individual or groups of users). User agents will assist the user by representing the characteristics and the preferences of the user, and are further characterized by the roles which the user plays. Examples of these agents are:

- Personal Assistants: assists the user in his tasks and responsibilities, working in cooperation with him

- Administrative assistant: relieves the user from the burden of routine and predictable tasks, such as filtering and conveying information to the user (e-mail, mobile computer, faxes, voice-mail,...) and scheduling meetings

- Role-specific agents: they provide high-level assistance to the user, specialized according to the role of the user ( e.g. designers, engineers, supervisors,...).

- Task-oriented Agents: designed to the execution of specific tasks, not necessarily on behalf of system resources, as for example, 
- Organizational agents: normally other agents report to the organizational agent, which itself may represent a department, project, division of the enterprise or the enterprise itself. They may have resources such as money, own a "timeline schedule", approve work and make settlements

- Service Agents: may represent high-level services, generally in client/server architectures, located at the server as well as at client side As it will be discussed later on this work they may be great importance for legacy systems, and reduced in the implementation to so called proxy objects. Examples of those agents may be:

- client agents: at client or server side, representing the interests of the client

- server agents: at the server or client side, representing the interests of the server

- license server;

- Resource agents: these agents represent exhaustible assets ( i.e. resources) of system or enterprise. One specific commodity among every agent managing a resource is that it has to be exclusive when it comes to access the variable representing the quantity of the resource. Otherwise some resource agents may represent the interests of multiple resources. Examples:

- Equipment agent: represents a specific physical resource (a "life-entity" in the real world). Such resources are usually characterized by having sensors and actuators and may be associated with humans operators. These agents can be so smart that they assume an "anthropomorphic" nature in respect to the physical resource they supervise

- Computational agent: representing computing resources

- Personal resource agents: because people are often treated as resources

- Information agents: information agents are primarily concerned with the managing, gathering and interpreting of information. Several kinds may be considered :

- Trading Agents are responsible for the negotiation of an information service because of the interest demonstrated by a user or because of the selling intention of a server; they receive a request from an application by some type of information service or they are asked to offer some specific information service to a community of users.

- Foraging Agents can be:

- Brokering Agents are responsible for managing system information objects on behalf of the applications that share them; they receive a request from an application, search the network object repositories for the information agent or server, and deliver a reference to it; they act as "Yellow Page" servers.

- Localization Agents are responsible by the exploration of the network in order to localize documents according to a user criteria. This user criteria could be simple as a pattern or very complex as a set of preferences constrained by established rules and dynamic conditions.

- Retrieval Agents are responsible for the retrieval of document content, along with information about its characteristics (which could be both spread through the network), at adequate data rates, in order to allow proper network transportation and presentation to the user. They are responsible by QoS (quality of service) negotiation and communication binding, recovery, and commitments of data flows.

- Cataloging Agents react to data events or other type of events in order to create, update, or destroy information in network data banks.

- Presentation Agents are responsible for the proper exhibition of information that arrives at the network node where the application has asked; proper exhibition means a combination 
of decompression, filtering, format conversion, language translation, synchronization, and user perception.

- Focusing Agents are briefed with a search profile, but the agent is looking for specific data items, like when a value threshold is reached; they are like database triggers, without the necessity to reside and depend on a database system. Once triggered the agent can deliver the information to the application.

\section{AGENT SKILLS}

\subsection{Agent Skills}

One way to achieve a general characterization for agents is through the use of the skill concept, borrowed from Minsky \{Minsky, 1994\}. An agent skill is a capacity that an agent presents (in some degree) that sometimes allows or facilitates the agent to play its role(s) and accomplish its goals.

We propose five major skills:

- intelligence or the degree of reasoning and learning ability of an agent;

- mobility or the degree of migration power of an agent;

- communicability or the degree of interaction ability of an agent;

- autonomy or the degree of auto-control ability of an agent and

- cooperation or the degree of an agent ability to collaborate and to do some joint work with other entities.

Each agent acting on some specific role has different graduations of each of these skills. Each of the skills is also related to a subset of the properties commonly cited in definitions of agents of various authors. Table 1 lists a set of such properties.

Table 1 Agent characterization properties

\begin{tabular}{|c|c|c|}
\hline Property & Other Name & Meaning \\
\hline activeness & self-start & $\begin{array}{l}\text { ability to decide when to act \{Hayes-Roth, 1995, Russel, } \\
\text { 1995, Franklin, 1996\} }\end{array}$ \\
\hline perceptiveness & sensing & $\begin{array}{l}\text { sensibility to (ability to receive information about) } \\
\text { changes in its environment \{Maes, 1995, Hayes-Roth, } \\
\text { 1995, Russel, 1995, Franklin, 1996\} }\end{array}$ \\
\hline reactivity & & $\begin{array}{l}\text { ability to respond to changes in its environment at just } \\
\text { the right time in order to be successful [Etzioni, 1994, } \\
\text { Wooldridge, 1995\} }\end{array}$ \\
\hline reflection & & $\begin{array}{l}\text { behavior in a quickly asynchronous stimulus-response } \\
\text { fashion \{Goodwin, 1993\} }\end{array}$ \\
\hline autonomy & & $\begin{array}{l}\text { exclusive control over its own actions \{Maes, 1995, } \\
\text { Smith, 1994, Brustoloni, 1991, Gilbert, 1995, Franklin, } \\
\text { 1995, Wooldridge, 1995, Franklin, 1996\} }\end{array}$ \\
\hline
\end{tabular}




\begin{tabular}{|c|c|c|}
\hline Property & Other Name & Meaning \\
\hline consideration & $\begin{array}{l}\text { goal-directed } \\
\text { purpose }\end{array}$ & $\begin{array}{l}\text { do not simply act in response to the environment, ability } \\
\text { to take the initiative to satisfy its own goals \{Maes, } \\
\text { 1995, Smith, 1994, Brustoloni, 1991, Franklin, 1995, } \\
\text { Wooldridge, 1995, Goodwin, 1993\} } \\
\text { do not blindly obey commands, but has the ability to } \\
\text { modify requests, ask clarification questions, or even ref- } \\
\text { use to satisfy certain requests \{Genesereth, 1994, Woold- } \\
\text { ridge, 1995\} }\end{array}$ \\
\hline independence & $\begin{array}{l}\text { asynchronous } \\
\text { operation }\end{array}$ & $\begin{array}{l}\text { may execute its tasks totally decoupled from its user or } \\
\text { other agents \{Gilbert, 1995\} }\end{array}$ \\
\hline communication & $\begin{array}{l}\text { socially able } \\
\text { interaction }\end{array}$ & $\begin{array}{l}\text { communicates with applications, facilities, services, } \\
\text { other agents and perhaps people, in order to obtain in- } \\
\text { formation or enlist their help to accomplishing its goals } \\
\text { \{Genesereth, 1994, Wooldridge, } 1995 \text {, Coen, } 1995 \text {, } \\
\text { Lingnau, 1995\} }\end{array}$ \\
\hline rule-based & & $\begin{array}{l}\text { possession of statements (rules) with preferences and } \\
\text { ability to choose what actions to take based on these } \\
\text { rules \{Gilbert, 1995\} }\end{array}$ \\
\hline ability to plan & $\begin{array}{l}\text { reasoning about } \\
\text { actions }\end{array}$ & $\begin{array}{l}\text { maintenance of some internal model of the world and } \\
\text { ability to reason about the results of the actions taken. } \\
\text { Tentative choose of actions that more likely lead it to } \\
\text { accomplish the task \{Hayes-Roth, 1995, Gilbert, 1995\} }\end{array}$ \\
\hline ability to learn & adaptability & $\begin{array}{l}\text { collection of information about the environment and its } \\
\text { use as knowledge in order to perform its task [Gilbert, } \\
1995 \text { \} }\end{array}$ \\
\hline $\begin{array}{l}\text { ability to pre- } \\
\text { dict }\end{array}$ & rationality & $\begin{array}{l}\text { the model of the world, if sufficiently accurate, allows } \\
\text { the correct prediction of what actions more likely lead to } \\
\text { accomplish the task successful \{Gilbert, 1995\} }\end{array}$ \\
\hline interpretation & & $\begin{array}{l}\text { interpretation of sensor readings \{Maes, 1995, Woold- } \\
\text { ridge, 1995\} }\end{array}$ \\
\hline soundness & & $\begin{array}{l}\text { if it is predictive, interpretive and rational \{Wooldridge, } \\
1995 \text { \} }\end{array}$ \\
\hline mobility & & $\begin{array}{l}\text { ability to transport itself or be transported from one ma- } \\
\text { chine to another, independently of the system architec- } \\
\text { ture and platform \{Heilmann, } 1995 \text { \} }\end{array}$ \\
\hline
\end{tabular}

\section{Intelligence}

Intelligence is the degree of reasoning and learning behavior that an agent contains. An agent employs some knowledge or representation of the user's goals and desires, in order to operate on behalf of the user.

An agent can present one of the degrees of intelligence listed below. The degrees are presented in order of increased complexity. Each degree includes its predecessors:

- preference - the agent acts according to some statements of the user's preferences. The user's preferences can be represented, for example, directly in the instructions (code) of the 
agent or by a set of rules. The agent can have an internal inference mechanism to process the rules or this mechanism can be provided by the platform;

- planning - the agent maintains some internal model of the world and of what the user wants to be done, and is able to choose what actions are more likely to lead it to accomplish its goals;

- reasoning - the agent reasons about the results of its actions and about the world, in order to choose the more appropriate actions to complete successfully its tasks. The agent presents some capacity for knowledge inference, data gathering, and extrapolation;

- learning - the agent learns and becomes able to adapt to a dynamic environment, both in terms of the user's objectives as in terms of the resources available to the agent. Such an agent may, for example, discover new relationships, connections, or concepts independently from the human user. Exploiting the acquired knowledge, the agent can make decisions, anticipating and satisfying user needs.

The intelligence of agents is associated with properties such as: rule-based, ability to predict, ability to plan, ability to learn, interpretation and soundness (see Table 1). An agent exhibits such properties depending on the level of intelligence it has or on the way the agent perform its tasks.

\section{Mobility}

Mobility is the degree of migratory power an agent exhibits. Agents can be dispatched from a source computer and roam over a set of networked servers until they accomplish their tasks. The list of migratory ability levels below is presented in order of increased complexity:

- static - the agent does not migrate. Although executing only in the platform of its user, such an agent may access not only local resources but also remote resources, for example via some kind of FTP command;

- remote execution (mobile without state) - remote execution of agents is realized through a remote procedure call, not necessarily synchronous, that asks for the execution of a program code existent in a remote node, or through a program, that may be composed on and dispatched from a client computer and whipped and transported to a remote server computer for execution. It can be seen as the distribution of a static (not initialized) agent to be executed at remote nodes;

- migration (mobile with state) - the agent migrates with information about its execution state. It can move from machine to machine in the middle of execution, and carries the accumulated information with it, in order to complete its tasks. When such an agent arrives at a remote node, it can present its credentials and so obtains access to services and data managed by the local software platform. Such a migration capability enables an agent to progressively accomplish its task while moving from place to place.

Very important to note is that a mobile agent decides to move by itself. That makes agent mobility different from the concept of migrating processes in some batch systems or distributed operating systems. In the latter case, processes are moved by some system coordination component, which tries to achieve, for example, load balancing.

\section{Communicability}

The communication skill represents the complexity degree of interactions an agent can perform with an application, a service, a facility, an user, or another agent. Communicability can be measured qualitatively by the nature of such interactions. The levels of communicability an agent can exhibit are listed below. The levels are presented in order of increased complexity: 
- isolated - the agent exhibits no capacity for interacting with any other entity;

- simple data exchange - the agent can interact through data exchange with other entities, with minor semantics in this interaction. Service calls with minor control information and some input data are characteristic of data exchange. Service responses are also communicated through data exchange. An agent can also monitor and respond to changes in the environment. Most of these changes are notified by asynchronous event driven communications, that is basically a data exchange communication;

- semantic data passing - the agent exchanges data with other entities but needs to interpret the semantics of the data in order to accomplish its tasks. An application domain vocabulary is needed to allow message passing. Semantic data can be exchanged between agents and other entities through message passing \{ Pitt, 1995\} or the blackboard \{Magedanz, 1995a . Messages exchanged between agents can represent, for example, an assertion (when it states a fact), a directive (if it includes a command, a request or a suggestion), or a declaration (when an agent sends an information on his internal capacities);

- conversation - the highest level of interaction between agents requires more than a conventional communication scheme in order to address the following issues: heterogeneity between agents, knowledge exchange, control localization and organizational structure \{Wong, 1993\}. Agents talk with their peers by exchanging messages in an expressive communication language with agent-independent semantics (it can not vary from one agent to another). The communication language allows for the exchange of data and logical information, individual commands and scripts. The conversation may involve several rounds of data exchange.

Depending on the level of its communication ability agents can present properties such as reactivity, perceptiveness and reflection (see Table 1). These properties result from the level of communication ability of the agent or the way this ability is used to perform the tasks.

\section{Autonomy}

Autonomy has been commonly used in the context of agents to refer to the principle that agents operate with or without the intervention of humans or others [Wooldridge, 1994, Nwana, 1996, Castelfranchi, 1994\}.

The autonomy of an agent reflects in the behavior of the agent in relation to external requests. If an agent acts only following orders, it does not exhibit much autonomy. If the agent has "its own goals" and can, therefore, accept or refuse external requests or do something that was not requested, then the agent exhibits more autonomy. This notion of autonomy is called Execution Autonomy by Castelfranchi \{Castelfranchi, 1994\}. Two major levels of autonomy can be observed:

- (restricted by) delegation: the agent executes tasks in behalf of the user, but the tasks it executes are constrained (or defined) by a delegation by the user (other agent or others);

- (based on) negotiation: when the agent has the ability to act on requests (accepting, refusing, negotiating) taking into consideration its own goals and capacities.

Autonomy is related to properties such as activeness, pro-activity, independence and consideration (see Table 1).

\section{Cooperation ability}

The cooperation ability of an agent relates to the degree with which the agent can establish and maintain a relationship to a set of other entities in order to perform a joint work. We 
identify the following degrees of cooperation ability. The list is presented in order of increased complexity:

- isolation - the agent executes its task by itself, it does not have ability to cooperate with other entities;

- static cooperation - the agent can cooperate with other entities, but in a static environment. The term static in this context means that the environment does not modify frequently. The rules and entities with which the agent can cooperate are relative stable and the agent has previously knowledge of them;

- dynamic cooperation - the agent is inserted in a dynamic environment, where components and rules constantly change. So agents are required to evaluate and compromise based on a range of preferences. Typically this type of cooperation involves a negotiation phase before the agent begins cooperating.

Figure1. Levels (degrees) of agents skills exhibited by different types of agents

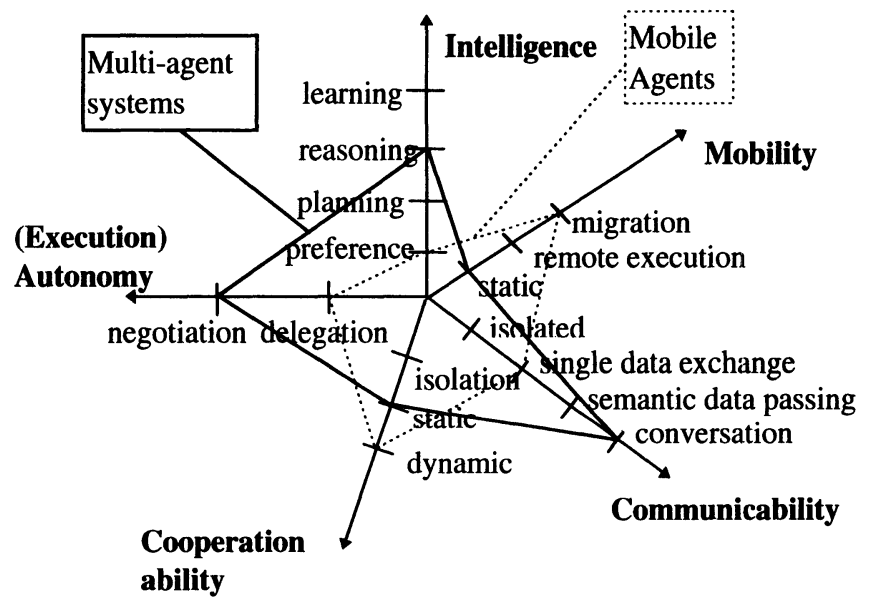

Figure 1 presents a graphical representation of the agent skills and their levels (degrees). The figure exemplifies also the degree of each skill that agents in different contexts (mobile agents and multi-agent systems) exhibit.

\section{CONCLUSIONS}

The future massive distributed systems bring together a set of new challenges for software engineering which cannot be suitably fulfilled by conventional distributed systems concepts. The support for mobile users and devices; the vast geographical extension; the huge dynamism allowing new information sources and servers to be added and removed without formal control and registration; the increasingly easier access to enormous amount of information; and high competition are only some of the characteristics of forthcoming systems.

The technology of agents converges developments in different software development areas and is emerging as the technology to fulfill those advanced requirements. Associated with 
notions of intelligence, mobility, autonomy, cooperation and communication (identified in the text as major agents skills), agents represent the building blocks of a new problem-solving paradigm which makes possible the development of very flexible, dynamic and adaptable systems. The exploration of the capacities of this emerging technology conducts us towards the prospect of how the future distributed systems will be.

This text aims at providing a compilation of the current research on the subject, trying to make clear what an agent is and what we can expect from them. Much effort has been expended in the development of theories and concepts to build the basis of the agents paradigm. An explosion of different types of contexts where agents are used is currently taking place. Efforts, however, must still be concentrated on the development of the technological support to make agent-based systems reality. That includes a more extensive investigation of the impact of agent technology in all the aspects of software engineering, from design up to implementation.

\section{ACKNOWLEDGEMENTS}

The authors are very grateful to Paulo Sérgio da Silva, Carlos Miguel Tobar Toledo, Ivo Fernandes, Carlos Raul Arias Méndez and Orandi Mina Falsarella from the UNICAMP and PUCCAMP Universities in Brazil. Much of this text resulted from their dedicated work.

\section{REFERENCES AND BIBLIOGRAPHY}

Note: Cited references are clearly marked by an asterisk after the author's name(s), e.g. name ${ }^{*}$. Unmarked references are included for bibliographical purposes.

\section{Agent Concepts and Theory}

_FAQ (1996) URL http://www.ee.mcgill.ca:80/ belmarc/agent_faq.html 1995.

OMG (1995) OMG Common Facilities RFP3, OMG TC Document 95-9-40, October,

Belgrave, M. ${ }^{*}$ (1995) The Unified Agent Architecture: A Platform for Intelligent Software Agents, Working Draft, revision 1.0, October. Available in http://www.ee.mcgill.ca/ $\sim$ belmarc/agent_root.html.

Brustoloni, J.C* (1991) Autonomous Agents: Characterization and Requirements, Carnegie Mellon Technical Report CMU-CS-91-204, Pittsburgh, Carnegie Mellon University.

Castelfranchi, C. * (1994) Guarantees for Autonomy in Cognitive Agent Architecture, Intelligent Agents, Lecture Notes in Artificial Intelligence, M.J.Wooldridge, N.R.Jennings (Eds.), Springer-Verlag, pp.56-70

Chess, D.M. et. al. ${ }^{*}$ (1995) Itinerant Agents for Mobile Computing, IEEE Personal Comm. Magazine, Vol.2 ,No. 5.

Coen, M. ${ }^{*}$ (1995) The Sodabot Slide Show, URL http://www.ai.mit.edu/people /sodabot/slideshow/P001/html.

Dalmonte, A. and Gaspari, M.* (1995) Modeling Interaction in Agent Systems. http://www.cs.umbc.edu/kqml/papers/gaspari-ijcai95.ps.

Eckardt, T. and Magedanz, T. ${ }^{*}$ (1996) From IN towards TINA-based Personal Communications Support, IEEE Int. Conference on Universal Personal Communications (ICUPC), Cambridge, Boston, September 29 - October 2, 1996. 
Etzioni, O. and Weld, D. S. (1995b) Intelligent Agents on the Internet: Fact, Fiction and Forecast, IEEE Expert, 4:44-49, August.

Etzioni, O. and Weld, D. S. ${ }^{*}$ (1994) A Softbot-based Interface to the Internet, Communications of the ACM, 37(7):72:76.

Etzioni, O. et al. (1995a) The Softbot Approach to OS Interface, IEEE Software, pp.42-51, July.

Franklin, S and Graesser, A. (1996) Is it an agent, or just a program?: A taxonomy for Autonomous Agents", http://www.msci.memphis.edu.

Franklin, S. * (1995) Artificial Minds, Cambridge, MA, MIT Press. Quoted in (Franklin, 1996).

Genesereth, M.R. and Ketchpel, S.P. ${ }^{*}$ (1994) Software Agents, Communications of the ACM, 37(7):48-53.

Gilbert, D. ${ }^{*}$ (1995), IBM Intelligent Agent Strategy White Paper, IBM Corporation, Research Triangle Park, NC, URL http://activist.gpl.ibm.com:81/WhitePaper/pct2.html.

Goodwin, R. * (1993) Formalizing Properties of Agents, Technical Report CMU-CS-93159, School of Computer Science, Carnigie-Mellon University, Pittsburgh, PA.

Harrison, C.G. et al ${ }^{*}$ (1994) Mobile Agents: Are they a good idea?, IBM Research Report, RC 19887, October 1994.

Hayes-Roth, B. ${ }^{*}$ (1995) An Architecture for Adaptive Intelligent Systems, Artificial Intelligence: Special Issue on Agents and Interactivity, 72:329-365. Quoted in (Franklin, 1996).

Heilmann, K. et al (1995) Intelligent Agents: A Technology and Business Application Analysis, http://haas.berkeley.edu/ heilmann/agents/.

Kay, A. (1984) Computer Software, Scientific American”, 251(3):191-207. Quoted in (Maes, 1994) and (Magedanz, 1995).

Lauer, G. et al. ${ }^{*}$ (1995) Broadband Intelligent Network Architecture, Intelligent Network Workshop (IN'95), Ottawa, Canada.

Lingnau, A and Drobnik, O. ${ }^{*}$ (1995) An Infrastructure for Mobile Agents: Requirements and Architecture, ftp://ftp.tm.informatik.uni-frankfurt.de/orlando.ps.

Maes, P. (1994) Agents that Reduce Work and Information Overload, Communications of the ACM, 37(7):30-40.

Maes, P. ${ }^{*}$ (1995) Artificial Life Meets Entertainment: Life like Autonomous Agents, Communications of the ACM, 38(11), 108-114. Quoted in (Franklin, 1996).

Magedanz, T. ${ }^{*}$ (1995a) Intelligent Agents: Concepts, Architectures and Applications,

Part 1 Intelligent Agents- state-of-the-art Analysis: Part 2: Impacts of Intelligent Agents Concepts on the Telecommunications Environment, FOKUS Report, Berlin.

Magedanz, T. ${ }^{*}$ (1995b) On the Impacts of Intelligent Agent Concepts on Future Telecommunication Environments", in: Lecture Notes on Computer Science 998 - Bringing Telecommunication Services to the People - IS\&N'95, pp. 396 - 414, A. Clarke et al. (Eds.), ISBN: 3540-60479-0, Springer Verlag, (Proceedings of the 3rd Int. Conference on Intelligence in Services and Networks (IS\&N), Heraclion, Greece, October 16-20, 1995)

Magedanz, T. and Eckardt, T. ${ }^{*}$ (1996a) Mobile Software Agents: A new Paradigm for Telecommunications Management, in: Proceedings of IEEE/IFIP Network Operations and Management Symposium (NOMS), Kyoto, Japan, April 15-19, 1996, pp. 360-369, IEEE Catalog No. 96CH35757, ISBN: 0-7803-2518-4, IEEE Press.

Magedanz, T. and Eckardt, T. ${ }^{*}$ (1996b) Mobile Service Agents and their Impacts on INbased Service Architectures, in: Proceedings of IEEE Intelligent Network Workshop, , Melbourne, Australia, April 21-24, 1996, IEEE Catalog No. 96TH8174, ISBN: 0-7803-3230-X, IEEE Press. 
Magedanz, T. et al (1996c) Intelligent Agents: An Emerging Technology for Next Generation Telecommunication?, Proceedings of IEEE INFOCOM, San Francisco, March 1996.

Minsky, M. and Riecken, D. ${ }^{*}$ (1994) A Conversation with Marvin Minsky About Agents, Communications of the ACM, 37(7):22-29.

Mohan et.al. " (1995) A Personal Messenger Application Based on TINA-C, XV. Int. Switching Symposium, Berlin, Germany, April 1995.

Negroponte, N. (1970) The Architecture Machine; Towards a more Human Environment, MIT Press, Cambridge, Mass. Quoted in (Maes, 1994) and (Magedanz, 1995).

Nwana, H.S. (1996) Software Agents: An Overview, to appear in Knowledge Engineering Review.

Ousterout, J. (1995) Scripts and Agents: The New Software High Ground. Invited talk, USENIX Conference. Quoted in (Lingnau, 1995)

Pitt, J. ${ }^{*}$ (1995) Normalized Interactions Between Autonomous Agents, http://medlar.doc.ic.ac.uk/

Reinhardt, A. ${ }^{*}$ (1994) The Network with Smarts, BYTE Magazine, pp. 51-64, October.

Rizzo, M and Utting, I.A. (1995), An Agent-based Model for the Provision of Advanced Telecommunication Services, pp 205-218, Proceedings of the 5th Telecommunications Information Networking Architecture (TINA) Workshop, Melbourne, Australia, February 1995.

Russel, S.J. and Norving P. ${ }^{*}$ (1995), Artificial Intelligence: A Modern Approach, Englewood Cliffs, NJ, Prentice Hall. Quoted in (Franklin, 1996).

Selker, T. (1994), Coach: A Teaching Agent that Learns, Communications of the ACM, 37(7):92-99.

Smith, D.C. et al (1994), KIDSIM: Programming Agents Without a Programming Language, Communications of the ACM, 37(7):55-67.

Virdhagriswaran, S. (1995a), URL http://www.crystaliz.com/logicware/mubot.html.

Virdhagriswaran, S. (1995b), Response to Request for Information (RFI) on Common Facilities - Common Intelligent Agent Services Specification (CIASS), OMG.

Wong, S.T.C. * (1993), COSMO: A Communication Scheme for Cooperative Knowledgebased Systems", IEEE Transac. on Systems, Man, and Cybernetics, 23 (3):809-824.

Wooldridge, M. and Jennings, N.R. ${ }^{*}$ (1994a), Agents Theories, Architectures, and Languages: A Survey in Intelligent Agents, Proceedings of. ECAI-94, Workshop on Agent Theories Architectures, and Languages, Lecture Notes in Artificial Intelligence, 890.

Wooldridge, M. and Jennings, N.R. ${ }^{*}$ (1995), Intelligent Agents: Theory and Practice, Submitted to Knowledge Engineering Review, October 1994, Revision of January 1995.

\section{Survey of $R \& D$ Projects}

- (1995) A Survey of Cognitive and Agent Architectures. In URL http://ai.eecs.umich.edu:80/cogarch0/

Coen, M. (1996). SodaBot: A Software Agent Construction System. Draft Version, URL http://www.ai.mit.edu/people/mhcoen/sodabot.ps

\section{Survey of AI Theory}

Agre, P. and Chapman, D. (1987) PENGI: An implementationof the theory of activity, In Proceedings of the Sixth National Conference on Artificial Intelligence (AAAI-87), pp. 268272, Seattle, WA. Quoted in \{Wooldridge, 1995\}.

Almasi, G. and Jannathan, V. (1996) Integrating the WWW and CORBA based Environments, Concurrent Engineering Research Center, West Virginia University, http:// webstar.cerc.wvu. edu/www4.html 
Barry Kitson, (1995) CORBA and TINA: The Architectural Relationships, TINA Symposium , Australia , May

Brooks, R. A. (1986) A robust layered control system for a mobile robot, IEEE Journal of Robotics and Automation, 2(1):14-23. Quoted in \{Wooldridge 1995\}.

Burmeister, B. and Sundermeyer, K. (1992) Cooperative problem solving guided by intentions and perception, In Descentralized AI 3 - Proceedings of the Third European Workshop on Modelling Autonomous Agents and Mutli-Agents Worlds (MAAMAW-91), Werner, E. and Demazeau, Y., editors, pp. 77-92, Elsevier Science Publishers B.V., Amsterdan, The Netherlands. Quoted in \{Wooldridge, 1995\}.

Chapman, D. (1987) Planning for conjunctive goals, Artificial Intelligence, 32:333-378. Quoted in \{Wooldridge, 1995\}.

Cohen, P.R. and Levesque, H. J. (1990) Intention is choice with commitment, Artificial Intelligence, 42:213-261. Quoted in \{Wooldridge, 1995\}.

Doyle, J.; Shoham, Y.; and Wellman, M. P. (1991) A logic of relative desire, in Methodologies for Intelligent Systems - Sixth International Symposium, ISMIS-91 (LNAI Volume 542). Ras, Z. W. and Zemankova, M., editors. Spring-Verlag: Heidelbeg, Germany. Quoted in \{Wooldridge, 1995\}.

Ferguson, I. A. (1992b) Towards an architecture for adaptive, rational, mobile agents. In Descentralized AI 3 - Proceedings of the Thrid European Workshop on Modelling Autonomous Agents and Mutli-Agents Worlds (MAAMAW-91), Werner, E. aand Demazeau, Y., editors pp. 249-262, Elsevier Science Publishers B.V., Amsterdan, The Netherlands. Quoted in \{Wooldridge, 1995\}.

Ferguson, I.A. (1992a) TouringMachines: An Architecture for Dynamic, Rational, Mobile Agents, PhD thesis, Clare Hall, University of Cambridge, UK. Quoted in \{Wooldridge, 1995\}.

Franklin, S., Graesser, A. (1996), Is it an agent, or just a program?: A taxonomy for Autonomous Agents, http://www.msci.memphis.edu, March

Georgeff, M.P. and Lansky, A.L. (1987) Reactive reasoning and planning, In Proceedings of the Sixth National Conference on Artificial Intelligence (AAAI-87), pp. 677-682, Seattle, WA. Quoted in \{Wooldridge, 1995\}.

Haddadi, A. (1994) A hybrid architecture for multi-agent systems, In Proceendings of the 1993 Workshop on Cooperating Knowledge Based Systems (CKBS-93), Deen, S. M. editor, pp. 13-26, DAKE Centre, University of Keele, UK. Quoted in \{Wooldridge, 1995\}.

Hintikka, J. (1992) Knowledge and Belief, Cornell University Press: Ithaca, NY. Quoted in \{Wooldridge, 1995\}.

Kiss, G. and Reichgelt, H. (1992) Towards a semantics of desires, In Descentralized AI 3 Proceedings of the Thrid European Workshop on Modelling Autonomous Agents and MutliAgents Worlds (MAAMAW-91), Werner, E. and Demazeau, Y., editors, pp. 115-128, Elsevier Science Publishers B.V., Amsterdan, The Netherlands. Quoted in \{Wooldridge, 1995\}.

Maes, P. (1989) The dynamics of action selection, In Proceedings of the Eleventh International Joint Conference on Artificial Intelligence (IJCAI-89), pp. 991-997, Detroit, MI. Quoted in \{Wooldridge, 1995\}.

Maes, P. (1990) Situated agents can have goals, In Designing Autonomous Agents, Maes, P. editor, pp. 49-70, The MIT Press, Cambridge, MA. Quoted in (Wooldridge, 1995\}.

Maes, P. (1991) The agent network architecture (ANA). SIGART Bulletin, 2(4):115-120. Quoted in \{Wooldridge, 1995\}.

Moore, R.C. (1990) A formal theory of knowledge and action. Readings in Planning, In Allen, J.F., Hendler, J., and Tate, A., editors, pp. 480-519, Morgan Kaufmann Publishers, San Mateo, CA. Quoted in \{ Wooldridge, 1995\}. 
Müller, J.P., Pischel, M., and Thiel, M. (1995), Modelling reactive behaivour in vertically layred agent architecutures, In Intelligent Agents: Theories, Architectures, and Languages, Wooldridge, M. and Jennings, N.R., editors, Lecture Notes in Artificial Intelligence, 890:261276, August.

OMG (1993) The Common Object Request Broker: Architecture and Specification, r.1.2, OMG Documentation.

Rao, A.S. and Georgeff, M.P. (1991a) Asymetry thesis and side-effect problems in linear time and branching time intention logics, In Proceedings of the Twelfth International Joint Conference on Artificial Intelligence (IJCAI-91), pp.498-504, Sydney, Australia. Quoted in \{Wooldridge, 1995\}.

Rao, A.S. and Georgeff, M.P. (1991b) Modeling rational agents within a DBI-architecture, In Proceedings of Knowledge Representation and Reasoning (KR\&R-91), Fikes, R. and Sandewall, E., editors, pp. 473-484, Morgan Kaufmann Publishers: San Mateo, CA. Quoted in \{Wooldridge, 1995\}.

Rao, A.S. and Georgeff, M.P. (1993) A model-theoretic approach to the verification of situated reasoning systems, In Proceedings of the Thirteenth International Joint Conference on Artificial Intelligence (IJCAI-93), pp. 318-324, Chambéry, France. Quoted in \{Wooldridge, 1995\}.

Rosenschien, S. and Kaelbling, L.P. (1986) The synthesis of digital machines with provable epistemic properties. In Proceedings of the 1986 Conference on Theoretical Aspects of Reasoning About Knowledge, Halpern, J.Y., editor, pp. 83-98, Morgan Kaufmann Publishers, San Mateo, CA. Quoted in \{Wooldridge, 1995\}.

Sacerdoti, E. (1974) Planning in hierarchy of abstraction spaces, Artificial Intelligence, 5:115-135. Quoted in \{Wooldridge, 1995\}.

Sacerdoti, E. (1975) The non-linear nature of plans, In Proceedings of the Fourth International Joint Conference on Artificial Intelligence (IJCAI-75), pp.206-214, Stanford, CA. Quoted in \{Wooldridge, 1995\}.

Singh, M.P. (1994) Multiagents Systems: A Theoretical Framework for Intentions, Know How, and Communications, (LNAI Volume 79), Springer-Verlag, Heidelberg, Germany. Quoted in \{Wooldridge, 1995\}.

Thomas, D. (1995) Ubiquitous Applications: Embedded Systems to Mainframe, Communication od the ACM, October.

TINA (1995a) Distributed Processing Environment (DPE), version 1.0, August.

TINA (1995b) Object Definition Language (ODL) Manual, version 1.3 June.

Tschammer, V. and Mendes, M.J. (1995): Architecture and Distributed Support Environment for Open Distributed Applications and Telecommunications Services, GMD FOKUS Berlin.

Wainer, J. (1994) Yet another semantics of goals and goal priorities, In Proceedings of the Eleventh European Conference on Artificial Intelligence (ECAI-94), pp.269-273, Amsterdam, The Netherlands. Quoted in [Wooldridge, 1995\}.

Wayner, P. (1995), Free Agents, Byte, March

Wooldridge, M. (1994b) Coherent social action, In Proceedings of the Eleventh European Conference on Artificial Intelligence (ECAI-94), pp.279-283, Amsterdam, The Netherlands. Quoted in \{Wooldridge, 1995\}.

\section{Agents applications}

Agent Incorporation* (1995) Firefly, reached at http://www.ffly.com/

Athan, A. and Duchamp, D. (1993) Agent-Mediated Message Passing for Conatrained Environments, Proc. Usenix Symp. Mobile and Location-Independen Comp. 
Bgrodia, R. et al ${ }^{*}$ (1995) Vision, Issues, and Architecture for Nomadic Computing, IEEE Personal Communications, December 1995

Borenstein, N., Freed, N. (1992) MIME (Multipurpose Internet Mail Extensions Part One: Mechanisms for Specifying and describing the Format of Internet Messages Bodies", RFC 1341, June

Borenstein, N.S. (1992) Computational Mail as Network Infrastructure for Computer Supported Cooperative Work, CSCW92 Proceedings, Toronto, November.

Borenstein, N.S. (1994) Email with a mind of its own: The SafeTcl Language for Enabled Mail, ULPAA, Barcelona.

Borenstein, N.S. and Rose, M.T. (1993) MIME Extensions for Mail-Enabled Applications: application/SafeTcl and Multiparty/enabled Mai", October.

Chess, D.M. et al (1995), Itinerant Agents for Mobile Computing. IEEE Personal Comm. Magazine, Vol.2 ,No. 5, October.

Chess, D.M. et al. (1994), Mobile Agents: Are they a good idea?, IBM Research Report, RC 19887, October.

Chu, W.W. ${ }^{*}(1996)$ CoBase: A Scaleable and Extensible Cooperative Information System, J. Intelligent Information Systems

Connolly, J.H. (1994b) Artificial Intelligence and CSCW in International contexts, in \{Connoly 1994a\}, pp 141-159

Connolly, J.H. and Edmonds, E.A. (editors) (1994a), CSCW and Artificial Intelligence, Springer Verlag.

Goyal, S.K. (1991) Knowledge technologies for evolving networks, Integrated Network Management II, Krishnan \& Zimmer (Eds), Elsevier Publishers.

Guilfoyle, C., Warner, E. (1994) Intelligent Agents: The New revolution in Software, Technical report, OVUM Limited.

Hauser, R. ${ }^{*}$ (1995) NetWatch Top Ten - Intelligent Agents / Information Agents, reached at http://www.pulver.com/netwatch/topten/tt9.html

Hoffman, D. L.; T. P. Novak; P. Chatterjfe, (1996) Commercial Scenarios for the Web: Opportunities and Challenges, to appear in Journal of Computer-Mediated Communication", Special Issue on Electronic Commerce.

IBM $^{*}$ (1995) Infosage, reached at http://www.infosage.ibm.com/, 1995.

Ida, I. et al (1995) DUET: An agent based Personal Communications Network, IEEE Communications Magazine, Vol. 33, No. 11, November.

ITU-T (1991) ITU-T Draft Recommendation F.851, "Universal Personal Telecommunications- Service Principles and Operational Provision", November.

ITU-T (1992) ITU-T Recommendations Q.12xx Series on Intelligent Networks, Geneva, March

Klein, S.; Langenohl, T. * (1994) Electronic Markets: An Introduction, In Proceedings of Information and Communications Technologies in Tourism, Wien, Springer-Verlag.

Le, M.T. et al (1995), Infonet: The Network Infrastructure of Infopad, Proc. CompCom, California, March

Liu,G., Maguire, G. (1995) Efficient mobility management support for wireless data services, Proc. 45th IEEE Vehicular Tech. Conf., Chicago, IL, July.

Magedanz, T. (1995c), On the integration of IN and TMN- Modeling IN based Service control capabilities as Part of TMN-based Service Management, ISINM 95, Santa Barbara, USA, May 1-5

Mazer, M. et al ${ }^{*}$ (1995) Issues in mobile Computing Systems. Guest Ediors Note in IEEE Personal Communications, Dezember. 
NIIIP (1996a) NIIIP Reference Architecture, National Industrial Information Infrastructure Protocols Consortium

NIIIP (1996c) National Industrial Information Infrastructure Protocols Consortium, Reference Architecture: Concepts and Guidelines, Stamford, CT, USA.

NIIIP* (1996b) National Industrial Information Infrastructure Protocols Consortium, Virtual Enterprise Computing: the Competitive Edge for the 21st Century, Stamford, CT, USA.

Open Applications Group,Inc. (1996), Open Application Group Integration Specification, document $\mathrm{N}^{\circ} 1996.02 .02$, version 1.002.0.

Ramjee, R. et al (1995), The use of Networked-Bsased Migrating User Agents for Personal Communication Services, IEEE Personal Communications, December.

Richardson, T. et al. (1994), Teleporting in an X Window system environment, IEEE Personal Comm., 3rd Quarter.

Schuster, H.; S. Jablonski; T. Kirsche; C. Bussler, (1994) A Client/Server Architecture for Distributed Workflow Management Systems", reached from World Wide Web as http://www6.informatik.uni-erlangen.de:1200/publ/sjkb94.ps.Z

TINA (1993) Telecommunication Information Networking Architecture -TINA Consortium, Dic No. TB_B.HT.004_1.0_93, Description of Telecom Service Examples, December.

Want, R. et al $^{*}$ (1995) An Overview of the ParcTab Ubiquitous Computing Experiment, IEEE Personal Communications, December.

\section{Technical requirements for the development of agents}

Colusa Software (1996), Colusa Software White Paper: Omniware Technical Overview, Colusa Software Inc.

\section{BIOGRAPHIES}

Prof. Dr. Manuel de Jesus Mendes received his Dipl.Ing. degree in Electrical Engineering in 1965 and a Dr.Ing. degree in 1968 at the Technical University of Berlin. He was a researcher from 1968-1969 at the Heinrich Hertz Institut in Berlin, and from 1969 to 1973 at the Max-von-Laue Paul Langevin Institut in Grenoble. Since 1973 he is full professor at the Electrical Engineering Faculty, Universidade Estadual de Campinas (UNICAMP) Brazil, where he retired in 1994. He became since then an invited professor at UNICAMP and is currently full professor at the Instituto de Informática, Pontifícia Universidade Católica de Campinas (PUCCAMP). His current research area is Open Distributed Platforms focused to telecommunications.

Dr. Waldomiro Loyolla received a B.S. degree in Physics in 1976 and in Electrical Engineering in 1980, a M.S. degree in Electrical Engineering in 1987, and a Ph.D. degree in Electrical Engineering from the Department of Computer Engineering and Industrial Automation at UNICAMP in 1992. He was a lecturer at the State University of São Paulo (UNESP) in Bauru since 1977, and was the Head of the Electrical Engineering Department from 1993 to 1995. Since 1996 he is a full Professor at the Informatics Institute at Pontifícia Universidade Católica de Campinas (PUCCAMP). His current research is directed to Workflow Management and Organizational Computing in Open Distributed Processing Environments. 
Dr. Thomas Magedanz is assistent professor at the Department for Open Communication Systems of the Technical University Berlin with focus on distributed computing and telecommunications. In addition, he is head of the "Intelligent Communication Environment" research department of the GMD Research Center for Open Communication Systems (FOKUS) in Berlin. He received his master's and $\mathrm{Ph}$. D. in computer science from the Technical University of Berlin, Germany in 1988 and 1993, respectively. Since 1989 he has been involved in several international research studies and projects related to IN, TMN, mobile computing and personal communications. In 1996 he was named project leader of the TINAC Auxiliary Project "Personal Communication Support in TINA".

Flávio Morais de Assis Silva received a B.S. degree in Computer Sciences from the Universidade Federal de Minas Gerais (UFMG), Brazil, in 1989, and a M.S. degree in Computer Sciences from the Universidade Estadual de Campinas (UNICAMP), Brazil, in 1993. He is currently a Ph.D. candidate at the Technical University Berlin, Germany. During 1995 he has contributed to the RACE Prepare Project. His areas of interest are Advanced Transaction Processing, Mobile Computing and Open Distributed Processing Environments.

Sven Krause received a Dipl.-Inform. degree in Informatics from the Technical University of Berlin in 1992. From 1993 until 1995 he worked at GMD FOKUS, the German National Research Centre for Information Technology's Research Institute for Open Communication Systems. His work there focused on system and service management for ATM-based VPN networks. In 1995 he joined the Institute for Open Communication Systems of the Technical University of Berlin. His research area is the application of agent technology for the rapid and customized provision of information and telecommunication services in dynamic environments characterized by user and end system mobility. 